\title{
Gender Responsive Pedagogy and Early Childhood Teacher Education: A Study of Pre-primary School Teachers in Nairobi County, Kenya
}

\author{
Juliet Njeri Muasya \\ Department of Educational, Communication, Technology and Pedagogical Studies, Faculty of Education, University of Nairobi, Nairobi, \\ Kenya
}

Email address:

n_juliet@uonbi.ac.ke,julietnjerim@gmail.com

To cite this article:

Juliet Njeri Muasya. Gender Responsive Pedagogy and Early Childhood Teacher Education: A Study of Pre-Primary School Teachers in Nairobi County, Kenya. Teacher Education and Curriculum Studies. Vol. 6, No. 3, 2021, pp. 101-108. doi: 10.11648/j.tecs.20210603.15

Received: August 13, 2021; Accepted: August 30, 2021; Published: September 6, 2021

\begin{abstract}
Gender responsive pedagogy, sometimes referred to as gender sensitive or gender flexible pedagogy is a key area recognised in 2015 Sustainable Development Agenda. In this 21 st Century, teachers continue to play a key role in the teaching and learning process, while being expected to transmit gendered values, knowledge and skills to learners in the most responsible and appropriate way/s. In addition, pre-primary teachers are charged with the responsibility of caring and rearing children in schools. This means that teacher's ideas and beliefs whether gendered or not are more likely to impact on the pre-primary school children's lives differently. Since children in their formative years nurture values, attitudes, life skills and virtues given to them by teachers, it means that teachers with gendered knowledge are likely to shape children's mindset in a positive way. The idea of integrating gender responsive pedagogy in teacher training curriculum is well stipulated in both national and international frameworks. In this paper the author will present and discuss findings of a study done among teachers in public pre-primary schools in Nairobi County. The aim of the current study was to examine the extent to which teachers are grounded on gender pedagogical discourses during their pre-service teacher training programmes. Findings reveal that although majority of pre-primary teachers are aware of gender issues, they seem to have limited knowledge on how to use gender responsive pedagogy. In this era of globalisation and with the introduction of Competency Based Curriculum in Kenya, there is a need to critically reevaluate teacher's in-service and pre-service training programmes in order to ascertain proper inclusion of gender related topics, courses or units, a way of facilitating achievement of gender equity and equality.
\end{abstract}

Keywords: Gender Responsive Pedagogy, Early Childhood Education, Teacher Education, Gender Equality

\section{Introduction}

Gender responsive pedagogy and teacher education are ways in which teachers engage with gender related practices especially when working with children. Gender flexible pedagogy is the idea of incorporating and integrating aspects gender discourses in the curricula [1]. Teacher education is a powerful programme aiming at changing attitude, knowledge, capacities, and skills, while raising gender consciousness among male and female teachers despite their traditional patriarchal mindsets $[2,4]$. Thus, there is need to integrate gender discourses in Early Childhood Education (ECE) curriculum, school culture, teaching methods, materials and pedagogy in teacher training education and programs as suggested by $[3,5,6]$. Gender flexible pedagogical discourses in ECE has the potential of 'undoing' the established traditional gender performances and practices [6]. Therefore, gender discourses should be considered in ECE teacher training and continuing professional development since it makes teachers aware of different aspects of gender issues, roles and responsibilities [6,7]. Knowledge of gender discourses is significant because teachers will be in a position to effectively teach children gender norms, attitudes and 
expectations of the society. As noted by Plan International [8], by the time children are in primary and secondary school they are already aware of how they are expected to behave in regard to their future roles and responsibilities as boys and girls who are members of a dynamic society.

A curriculum covering aspects of gender and pedagogy is likely to make teachers challenge and deal with different forms of stereotypes. Teacher's attitudes, practices and different expectations of children in school can reproduce gender stereotypes, which can affect the motivation, participation, learning outcomes, and the choices boys and girls make in life $[3,7]$. Gender sensitive teachers ensure unbiased participation of boys and girls, which then place teachers in a better position to challenge stereotypes and discriminatory social norms in the curriculum, instructional resources and other pedagogical practices [9]. Teachers with knowledge of gender pedagogy are more likely to make preprimary school children be in a position to question traditional gender roles and attitudes, while being able to point out gender biases, inequalities and stereotypes, a way of achieving gender equality [9, 10].

Gender responsive pedagogy improves participation of boys and girls, promote positive attitudes and behaviours during the teaching and learning process especially when one is using diversity of teaching and assessment styles [7]. According to Nabuyye [10] such pedagogical practices will help boys and girls to equally participate in group discussions, debates, field study trips, project-based learning and presentations. Improved classroom participation and performance of children as a result of gender sensitive pedagogy has further been confirmed by $[10,11]$. There is evidence to show that gender pedagogical program by Forum for African Women Educationalists (FAWE) implemented in Malawi, Tanzania, Ethiopia, Gambia, Kenya and Zambia changed teachers' attitudes and practices, increased girls' access to and participation in school, enrolment and enhanced retention [10]. Further, girls' self-esteem is usually enhanced when teachers use gender pedagogical practices, while aligning pedagogy to the specific needs and interests of girls and boys [12].

Teachers who are familiar with the factors that influence formation of children's gender identity and stereotype can effectively counteract and neutralise gender bias in the classrooms and prevent formation of gender stereotypes [13]. There is need to integrate gender-neutral, sensitive and responsive pedagogical issues in teacher professional development. This will enable pre-primary school teachers to consciously challenge gender stereotypes before it becomes a constant way of thinking while providing a genderresponsive environment in which children can develop their full potential.

Gender responsive pedagogy is likely to open up more opportunities for children's growth and development irrespective of their gender. Gender pedagogy in teacher training programmes create equality and equity among boys and girls, which then help them to optimize their natural talents and opportunities [11]. Research has shown that when teachers are trained on gender and pedagogical discourses, more girls tend to benefit. For instance, girls are more likely to remain in school for a longer period, while parents might be convinced to send girls to school, which could make them attain higher levels of education [10]. In addition, Nabbuye [10] noted that gender-sensitive pedagogy can make girls engage and excel in Science, Technology, Engineering and Mathematics (STEM), where they gain relevant skills to enable them to compete in the labour market in line with post 2015 sustainable development goals.

Gender responsive pedagogy provides a safe learning environment for boys and girls. This means that gender sensitive pedagogy and classroom management can reduce teacher bias, build supportive, safe and friendly environment for all children. Teachers who understand gender discourses use knowledge and skills acquired during their training to enhance school safety, making the school environment more equitable spaces for boys and girls [7], while being able to challenge gender discrimination and violence. I further concur with the sentiments given by Plan International [8] and Nabbuye [10] that the benefits of using gender responsive pedagogy lead to empowerment and quality educational outcomes for boys and girls.

Further, gender responsive pedagogy leads to achievement of SDG 4; gender equality in education. It is important to note that gender responsive teachers have the knowledge and skills to shape pre-primary school children's mindset. Thus, training teachers to be gender responsive is an effective intervention strategy of bringing progressive changes, while minimising gender discrimination and bias in society [4]. Gender responsive teachers will be in a better position to disseminate desirable attitudes based on mutual respect and trust between girls and boys, since they understand the relevant knowledge, skills and methodologies that promote gender equality. Thus, for gender equality to be a 'lived' reality in the classroom, teachers need to practice gender responsive teaching [12]. Research points on the need to provide teachers with appropriate and focused gender sensitive education and training $[12,14]$. Such training will make teachers understand gender hierarchies, roles, power dynamics, while empowering them to challenge different forms of gender related discriminations $[7,14]$ in and beyond classroom settings. What this means is that gender transformative ECE programmes are a powerful window of opportunity which will go a long way in promoting development of children, while advancing gender equality and equity in society $[10,14,15]$. Working with gender discourses in teacher education programmes embraces policies and practices which involves formulating genderresponsive policies and plans, working with institutional culture, environment and teacher attitudes, in order to design gender sensitive pedagogical curriculum, and instructional materials [16]. According to Kreitz-Sandberg [17], by integrating gender discourses in ECE training programmes this will help teachers develop social sustainable practices that builds on gender equality and fairness across different pedagogical practices. 


\section{Literature Review on Gender Responsive Pedagogical Practices and Teacher Education}

In 2008 and 2009 Eurydice Network countries did a study and found out that gender does not seem to have a prominent place in pre-service teacher education programs and it is only included as a topic in the continuing professional development programs [18]. Further, the inclusion of gender discourses depends on institutions' initiative and learner's motivation to study gender related courses. Policies on teacher education fail to take into account gender perspectives either with respect to critical training or continuing professional development activities for teachers or headteachers. Similarly, findings from studies done by United Nations Girls Education Initiative on gender in teacher education and training in the global south, shows that there are few if any teacher education models that integrate gendered approaches into pedagogy. To be able to deal with gender equality, power dynamics, issues of human rights and violence, gender discourses should be integral part of preand in-service teacher training programmes [19].

In a study done among teachers in primary colleges in Zimbabwe, Rutoro, Jenjekwa, Julius and Chipato [20] explored the extent to which teacher education is preparing teachers to be gender equity agents in $21^{\text {st }}$ Century. The researchers used questionnaires, documentary analysis guide and interviews to collect data from trained and untrained teachers and lecturers. Findings revealed that lecturers and student's teachers have limited knowledge on gender debate and equality in the workplace. They lack awareness on the importance of integrating gender discourses in teacher education. Gender issues are silent in teacher education programmes in Zimbabwe. Majority of the respondents noted the need for an in-depth approach to gender education and its inclusion in teacher training programmes, as a standalone subject and not integrating it into other subjects. This is important if teachers have to effectively be equipped with the appropriate and relevant gendered discourses. The gendered knowledge can make teachers effective agents of social transformation, gender justice and equality. While the study was done among teachers, lecturers and student's teachers in primary colleges in Zimbabwe, data presented in this paper was drawn from 15 pre-primary school teachers in Nairobi County and ECE curriculum designs from two public universities in Kenya.

Reader [4] did a study in Kerala, India with the aim of understanding teacher trainee's perceptions of their gender roles. Reader used a sample of 632 students (390 girls and 242 boys), with 320 Hindus, 240 Muslims and 72 Christians drawn from 20 Bachelor of Education (Teacher Education) colleges of Kerela. In collecting and analysing data, Reader used an inventory on Gender Role Perceptions and SPSS respectively. Findings show a significant difference between gender role perceptions of males and females. Reader highlights the need to introduce discourses of gender studies in the orientation and in-service teacher training programmes. Reader's recommendation was based on the need to organise a five-day orientation and refresher programme on gender studies for teachers in higher education to help them meet the needs of $21^{\text {st }}$ century; especially in promoting gender justice and democracy.

Minimal attention has been given to gender training programmes, even in countries like Belgium, France and Switzerland who seem to have made great strides in addressing gender inequality in key areas of development Baudino 2007 in (UNESCO and UNGEI) [7]. Results of the review of education policies in 40 developing countries by Hunt (2013) in (UNESCO and UNGEI) [7], shows that policies that integrate gender training into teacher education remain scarce. In addition, Chi [11] noted that the actual policy and practice of incorporating gender perspectives in ECE teacher training has been overlooked. Even where such strategies exist, lack of clarity, inadequate resources and poor implementation, supervision and evaluation limit their effectiveness. There is still lack of knowledge on the extent to which teachers are trained in gender issues.

In a study done in kindergarten and preschools in Indonesia and Sweden respectively, Warin and Adriany [6] examined the extent to which 'gender flexible pedagogy' has been integrated into ECE programme. Data was collected using discussions and interviews with the pre-school teachers with the aim of understanding the potential of 'gender flexible pedagogy', while identifying how it can be practiced. Findings from the study done in Indonesian reveal that teachers' accounts of their practices and underlying assumptions were highly gendered. Teachers were able to differentiate the needs and interests of boys and girls during the teaching and learning process. Although findings reveal that majority of teachers uphold strong gender essentialist beliefs, they however did agree on the importance of treating boys and girls equally.

Regarding teacher's familiarity with gender principles in Swedish ECE curriculum, Warin and Adriany [6] found that teachers were aware of explicit gender goals enshrined within the curriculum. Male teacher's readiness in displaying knowledge of gender principles in the curriculum suggests a high degree of gender consciousness. The fact that male teachers are aware that Swedish curriculum counteracts traditional gender behaviour, this is a possible indicator of the extent to which they are gender sensitive which helps to make children less constrained by traditional and rigid forms of gender. However, in contrast with Indonesia, Sweden is known for its long-standing progressive focus on gender, childcare and education. This explains why Swedish male teachers are more "gender sensitive" as compared to those from Indonesia. Warin and Adriany [6] noted the need to make early childhood educators gender conscious to enhance effective use and implementation of gender pedagogical discourses.

In a study done among academic staff in Sokoine University of Agriculture, Kahamba, et al [9] assessed level of awareness in gender responsive pedagogical discourses. In 
particular, Kahamba, et al [9] explored the extent to which academic staff are aware of gender sensitive teaching techniques, and whether gender discourses are integrated in the day-to-day teaching and learning practices. Using a crosssection survey design and a questionnaire, the research team collected data using 83 academic staff randomly sampled, while adopting SPSS to generate descriptive statistics. The findings reveal that academic staff are partially aware of gender sensitive pedagogical practices. Drawing from these study findings, the research team noted the need for universities to continue with their gender campaigns and training workshops for academic staff. While the study was done among academic staff at Sokoine university in Tanzania, the current study used teachers drawn from public preprimary schools in Nairobi County.

Nabbuye [10] explored the benefits and challenges of implementing gender sensitive pedagogy using 70 teachers and 109 students in secondary schools from eastern and central Uganda. The study findings pointed out that although gender sensitive pedagogy is integrated in early childhood, primary, secondary curriculum and in-service trainings, there is lack of adequate guidelines and strategies in the implementation process. This means that gender pedagogical approach has not been fully translated into classroom practices. Further, findings reveal that $45 \%$ of teachers in Uganda had not been trained on how to use gender-sensitive pedagogy, while $43 \%$ reported that the training was done in less than a week, $13 \%$ had training ranging from two weeks to a month, and $26 \%$ received training for more than a month. Duration of training is likely to raise teachers' understanding on how to use gender responsive pedagogical practices. Although some teachers were willing to use gender responsive pedagogical tools, large classrooms and unsupportive system, meant that the application and implementation of pedagogy remain a challenge. Without proper training in gender responsive pedagogy, teachers may lack the confidence to effectively implement it. Use of gender pedagogical discourses could lead to achievement of gender equality, since the discourses specifically utilise methods which give boys and girls equal opportunities to participate in a variety of classroom activities.

An evaluation study done by Lahelma and Tainio [21] in Finland aimed at finding out how sustainable impact of TASUKO project 2014-2016 was used to promote gender equality and awareness among teachers. The researchers used an open-ended questionnaire and interviews with teachers, analysed project documents and teacher education curriculum Results from the analysis of materials and courses suggested that most institutional curricula had few gender courses, textbooks and other materials that draw theoretical and empirical results of Finnish and international gender studies. In some universities, there were course materials used to provide gendered knowledge and perspectives. Responses from Finnish teachers suggests that TASUKO project had a positive impact, as is evidenced by the integration of gender courses in the curriculum for both bachelors and a few masters programmes across all universities.
Estonia, Mägi, Biin, Trasberg and Kruus [22] did a study in the University of Tartu with the aim of examining level of gender awareness of students based on the labour market behaviour. Using a mixed method approach (focused group interviews, open ended questionnaires and semi-structured), the research team collected data from 2,748 students with the exemption of doctoral students. Data collected was analysed using statistical and qualitative content analysis. Results from the study shows a low level of awareness of the importance of gender deeply rooted in predispositions and attitudes towards gender equality and low competences. Student teachers noted that the awareness of gender issues is necessary and that gender related topics should be integrated into bachelors and master's degree programs and curriculum. Student trainees expressed high demand and attractiveness of course content that addresses discourses of gender equality. If teacher trainees are enlightened on gender issues, it means that the next generation is likely to have a deeper knowledge of gender discourses and less stereotypical attitudes. This will lead to achievement of gender equality.

Using data from baseline, midterm and end-line surveys, Ananga [23] explored how gender responsive pedagogy is being implemented during the initial training of student teachers in 46 Colleges of Education in Ghana. The aim of the study was to observe changes that had occurred since the implementation of gender responsive pedagogy in the curriculum of the Colleges of Education. The study used a combination of stratified, multistage, systematic random sampling techniques to obtain data from 310 participants (280 college tutors, 10 student teachers and 20 mentors) through lesson observations, interviews and questionnaires. The findings reveal a significant improvement in the use of gender responsive pedagogy in the core subjects (English, Mathematics and Science). Both male and female tutors demonstrated an increase in using gender responsive pedagogy in their teaching. A key recommendation is the need to mandate mentors and tutors to continuously use gender responsive pedagogy in their teaching. The Ministry of Education and Ghana Education Service should include gender discourses in the capacity building programmes and curriculum.

Despite emerging evidence on the need to sensitise preprimary teachers on gender discourses in order to challenge unjust gendered norms and attitudes from an early age, [11] reveals that few countries have focused their studies on gender equality in early childhood teaching and learning. From the studies reviewed, only researchers in Sweeden and Indonesia Warin and Adriany [6], Tanzania Kahamba, et al [9] and Finland Lahelma and Tainio [21] explored the issue of gender pedagogical discourses and practices in ECE. It is no wonder that Chi [11] pointed out that studies on gender pedagogical practices among ECE teachers continue to receive less attention, so far no such a study has been done in Kenya. While researchers like Nabbuye [10] explored the benefits and challenges of implementing gender pedagogical discourses in secondary schools in Uganda; Mägi et al [22], examined the level of gender awareness among University of Tartu students in the labour market, as Miske [19] reviewed studies done on gender in teacher education and training in 
the global south. Lack of research on gender and teacher education in ECE, more so in Kenya, did motivate the researcher to undertake the current study. In addition, although studies by [4, 10, 20, 21, 22, 23] were done at primary, secondary, training colleges and universities, they did partly inform the current study on the need to review ECE curriculum, in order to establish the extent to which gender discourses are integrated.

\section{Methodology}

In this study, the researcher used cross-sectional design since the information or data collected represents what actually transpired at that particular point in time, Oslen and St. George [24] or produces what Cohen, Manion and Morrison [25] refers to as a 'snapshot' of the data at a specific time. A total of 20 public pre-primary schools in Kasarani Sub- County, Nairobi were randomly sampled. Through purposive sampling procedure, only 15 (1 male and 14 female pre-primary school teachers) participated in the study. In depth interviews were used to explore pre-primary school teachers' views regarding gender pedagogical discourses. In addition, the researcher used documentary analysis guide to find out the extent to which gender topics or units are included in ECE curriculum designs from University of Nairobi and Kenyatta at different levels of degree programmes (certificate, diploma, bachelor, Masters and $\mathrm{PhD}$ ). Discourse analysis was used to analyse data from the interviews in line with the study objective. Discourses are knowledge structures through which researchers are able to understand and explain the relevance of aspects being studied (Foucault (1993) in Karlson and Simonsson [1]). In line with the post-structural context, discourses are concerned with what is said and how what is said influences what we do to constitute our world in certain ways and orders [1].

In addition to using discourses analysis to derive key themes in line with study objectives, codes were used to report verbatim responses from pre-primary school teachers, for instance codes (PPFT1 refer to Pre-Primary Female Teacher 1, while PPMT1 refer to Pre-Primary Male Teacher 1). Use of letters, numbers or pseudonyms is meant to protect privacy of the participants [26]. Data from the analysed ECE curriculum designs was corroborated with the verbatim findings from the interviews with the pre-primary school teachers as presented and discussed in the next section.

\section{Presentation and Discussion of Findings on Gender Responsive Pedagogy and Teacher Education}

\subsection{Demographic Data of Pre-primary School Teachers}

Out of 15 pre-primary school teachers who participated in this study, 12 female pre-primary teachers had a certificate and diploma in ECE as part of their professional qualification, while 2 ( 1 male and 1 female teachers) had a Bachelor of
Education in ECE. Only one female pre-primary teacher had a Master of Education degree in ECE. Cultural aspects, stereotypes, lack of social prestige and low salaries have been cited as reasons for gender imbalances among pre-primary school teachers [27].

\subsection{Pre-Primary School Teachers Knowledge of Gender Responsive Pedagogy}

In assessing pre-primary school teachers' knowledge of gender pedagogy, the current study was informed by $[6,9,11$, 21]. Out of 15 pre-primary teachers, 13 of them said they were familiar with gender related terminologies like gender equality principles, discrimination and gender sensitivity. In explaining their understanding of gender responsive pedagogy two pre-primary school teachers said: '...respecting boys and girls...to treat them equally unless a child has specific needs...' (PPFT 1); '...Gender equality which entail treating boys and girls the same and avoiding discrimination...' (PPFT 4).

Although there is evidence that pre-primary school teachers are aware of gender related issues, like was the case with the findings of the study by $[6,9,10]$, however, a number of teachers do not use gender responsive pedagogy. For, instance, Muasya and Kazungu [28] found that some pre-primary teachers rarely use gender related activities, and that the play activities used are characterised by gender stereotype messages. This as Nabbuye [10] noted is probably due to lack of proper training on how to effectively use gender responsive pedagogical practices, which makes teachers lack confidence. It is clear that if teachers lack gender responsive pedagogical knowledge, there is a possibility for girls to lack motivation or even fail to be active participants in various class activities like their male counterparts [10].

\subsection{The Status of Gender Discourses in ECE Teacher Curriculum Designs}

The task of reviewing ECE curriculum designs in the current study was informed by a number of scholars, namely Reader [4], Nabbuye [10], Rutoro, et al [20], Mägi, et al [22]. The researcher analysed ECE curriculum programmes (certificate, diploma, bachelor, masters and $\mathrm{PhD}$ levels) of Kenyatta University and University of Nairobi with the aim of finding out whether gender discourses are included or not. Findings from Kenyatta University ECE curriculum designs shows a gender course referred to as 'Gender Education', while in the University of Nairobi, there is a topic 'Gender concerns' in the unit of African Childhoods both at the $\mathrm{PhD}$ level. The ECE curriculum design from the University of Nairobi has an elective unit 'Gender studies and ECE', and a topic on 'role of boys and girls in the family' in the unit of 'Family studies and ECE' all at Bachelor of Education degree.

Findings from the two curriculum designs shows that gender discourses are either included as a topic or a complete unit. It seems that there is more coverage of gender related topics and units in the University of Nairobi's as compared to 
Kenyatta University's ECE curriculum designs. Results from Kenyatta University ECE curriculum design corroborates with the findings of studies done in 2008 and 2009 by Eurydice Network. The findings reveal lack of adequate coverage (only a topic) of gender principles in pre-service teacher education training programs. Similarly, other findings by Warin and Adriany [6], Nabbuye [10], Kreitz-Sandberg [17], Lahelma and Tainio [21] shows inclusion of gender discourses in ECE and primary school curriculum in Sweden, Uganda and Finland, like was the case with University of Nairobi. As Nabbuye [10] stated ECE teachers should avoid teaching gender responsive pedagogy as a separate topic, instead it should be embedded into teacher training programmes. However, it is important to note that students undertaking Bachelor of Education (ECE) at the University of Nairobi are more likely to be empowered with gender related knowledge, skills and attitudes when teaching preprimary school children as compared to those from Kenyatta university. Further, Kreitz-Sandberg [17] noted that gender inclusion as a pedagogical practice in teacher education has the potential of empowering pre-primary school children with relevant values, knowledge and skills, a precondition to improving sustainable pedagogical practices in ECE. It is important to note that the $21^{\text {st }}$ century teachers require continuous professional development and support in implementing and enhancing gender pedagogical discourses in ECE [11]. That is probably why Murru, Nawa-Chimuka, Vandenbosch and Doroba [13] noted that the idea of raising awareness on gender equality through gender pedagogical programmes should start at an early age, since this is the time children's characters are forming. In particular, Murru, et al [13] further noted that early intervention, through genderresponsive pedagogy at a time when children's brains and social identities are rapidly developing, has a better impact. This is because children develop self-awareness, basic values, attitudes and stereotypes which impact on their roles and position in society. Therefore, early years education has a greater potential of making children gender-sensitive [13], thus, the need for policy makers, curriculum developers and designers to make sure gender content or units are included in ECE curriculum for teacher education.

The need to incorporate gender pedagogical discourses in teacher training courses and programmes, particularly in ECE if gender equality has to be achieved continues to be emphasized by key researchers [4, 10-13, 20, 23]. Further, gender pedagogical discourses should be fully defined in teacher education policy frameworks at all levels $[10,20]$. In contrast to study done by Hunt 2013 in UNESCO and UNGEI [7] which shows that educational policies rarely integrate gender aspects in teacher training, Kenya's Sessional Paper No. 1 of 2019 on Policy Framework in Education and Training has clearly stipulated the importance of including gender pedagogical practices in teacher training programmes. Teachers in the $21^{\text {st }}$ Century need continuous professional development and support if they have to transfer gender responsive knowledge, skills and attitudes to all children $[11,20]$. This will go along way in facilitating the achievement of SDG 4.7 which emphasis Education for Sustainable Development which includes gender equality and human rights, be mainstreamed in national education policies, curricula and teacher education at all levels.

\subsection{Responses of Pre-primary School Teachers on Gender Responsive Pedagogy and Curriculum Designs}

Sometimes student trainees express high demand and attractiveness of course content addressing aspects of gender equality [22]. In discussing the need to integrate gender pedagogical discourses in teacher training curriculum, five out of 20 pre-primary teachers interviewed revealed that such knowledge will make them be able to handle boys and girls without discrimination, deal with stereotyped practices, thus lead to achievement of gender equality. Four of the preprimary teachers said: '...so that we can handle the children properly without discriminating them on the basis of gender, to understand their problems so as to come up with appropriate solutions to these problems...' (PPFT 1); '...so that we can know how to handle both boys and girls without discriminating either of the gender...' (PPFT 4); '...to avoid discriminating on the children therefore I will be able to give them equal opportunities to participate in all activities...' (PPFT 5);'...I think it is important...it is important that we understand boys and girls should be treated equally and also know themselves and their place in the society so they don't mess up later in life..'. (PPFT 6).

There is need to have a component of gender studies in ECE curriculum since this will make teachers treat boys and girls the same as reported by PPFT 7. This is likely to lead to achievement of gender equality once teachers know how to deal with the boy child who seems to be more vulnerable. PPFT 7 says: '...study of gender is important because some value the boy child more than the girl child and vice versa. It is important that they know all children are important and should be treated equally...'. PPFT 11 said: '...the male child seems neglected in the teaching of preschoolers...they feel that preschool teachers should be for females...'.

Sentiments by the pre-primary teachers concur with the findings of studies reviewed on the importance of integrating gender responsive pedagogical discourses in the ECE curriculum. This is because some researchers noted that any effort to include gender principles in the curricula, course assignments, school culture, teaching materials and methods in teacher training programmes will go a long way in making teachers more conscious, aware and sensitive to gender issues [2, 3, 16, 19, 22]. Gender pedagogical discourses contain ideas aimed at treating boys and girls differently, thereby facilitates achievement of gender equality and equity related goals [1] both in schools and society at large.

Researchers like Kahamba and Kira [9], Lahelma and Tainio [21] have clearly pointed out that if teachers lack adequate competencies and training on how to handle boys and girls, even gender friendly curricula and textbooks may be distorted and used ineffectively. Thus, well trained teachers can help deal with shortcomings in curricula and textbooks, while being able to interpret how such materials 
can be used to address gender stereotyping, a way of promoting gender equality [9]. Since teachers play a critical role in facilitating learning free of gender biases, gender sensitive training should be mandatory for all teachers, especially those interacting with children [12] irrespective of differences in curriculum designs.

\section{Conclusion}

Gender equity and equality principles should be central in pre-service and in-service teacher education and training programmes. As scholars continue to re-think about teacher training in the $21^{\text {st }}$ century and beyond, there is need to equip pre-primary teachers with relevant gender pedagogical practices to enable them understand the nature of gender stereotyped behaviours in order to overcome any possible barriers which could hinder effective teaching and learning process. Pre-primary teachers need to be equipped with gendered theoretical knowledge to enable them revisit their thinking and practices concerning gender issues among children in their day-to-day life. The integration of gender pedagogical discourses in teacher training programmes facilitates achievement of gender equity and equality as stipulated in $[29,30]$. In particular, SDG Target 4.7, commits countries to ensure that learners acquire knowledge and skills in sustainable development, human rights, gender equality and global citizenship. Lastly, there is need to undertake similar research in other counties and sub-counties in Kenya to validate findings of this current study.

\section{References}

[1] Karlson, I. \& Simonsson, M. (2011). A Question of gender sensitive pedagogy: Discourses in pedagogical guidelines. Contemporary Issues in Early Childhood, 12 (3).

[2] Helakorpi, J. Hynminen, P. Ikavalko, E. \& Lehtonen, J. (2010) Research on gender awareness in teacher education, TASUKO PROJECT, funded by the Ministry of Education (2008-2010), Working towards a research program on gender awareness in teacher education and in pedagogical practices.

[3] Lahelma, E. (2011). Gender awareness in Finnish teacher education: Impossible mission? Education Inquiry, 2 (2). 263 276.

[4] Reader, M. K. (2013). Gender studies components in teacher training: An essential requirement for teacher empowerment and gender justice in the 21 st century. International Journal of Education and Psychological Research, 2 (2). 46-50.

[5] Abraham, F. F. \& Sommorkorm, I. N. (1996). Promoting gender awareness in the classroom: An example from Germany, University of Hamburg.

[6] Warin, J. \& Adriany, V. (2015). Gender flexible pedagogy in early childhood education, Journal of Gender Studies, XX, X. $1-12$.

[7] UNESCO \& UNGEI (2015). The 2015 EFA global monitoring report, Gender and EFA 2000-2015, Achievements and challenges, UNESCO, Paris, France.
[8] Plan International (2017). Gender inequality and early childhood development, A review of the linkages, Plan International, UK.

[9] Kahamba, J. S., Massawe, F. A. \& Kira, E. S. (2017). Awareness and practice of gender responsive pedagogy in higher learning institutions: The case of Sokoine University of agriculture, Tanzania. Journal of Education Humanities and Sciences, 6 (2). 13-20.

[10] Nabbuye, H. (2018). Gender Sensitive Pedagogy: The bridge to girls' quality education in Uganda. Echidna scholars' program, policy brief, November 2018, Centre for universal education at Brookings, Washington, DC.

[11] Chi, J. (2018). The importance of gender in early childhood teacher education, Brookings Institution, Washington DC, USA.

[12] UNESCO (2016). Concept note: Regional training on gender assessment in teacher education in Asia, 25-2 $7^{\text {th }}$ May 2016, Bangkok, Thailand.

[13] Murru, A. C., Nawa-Chimuka, D., Vandenbosch, T. \& Doroba, H. (2017). Gender responsive pedagogy for early childhood education (GPPSECE), No. 3, FAWE conference on girls' education in Africa, $23^{\text {rd }}$ August, 2017, Lusaka, Zambia.

[14] Levtov, R. (2014). Gender equality and development, women's voice and agency research series 2014, No. 9, Addressing gender inequalities in curriculum and education: Review of literature and promising practices to improve education reform initiatives in Thailand, World Bank Publication.

[15] Miske, S. (2017). How can teachers be more gender inclusive in the classroom. (Unpublished paper).

[16] UNESCO (2015). A Guide for gender quality in teacher education, policy and practices, Paris, France. UNESCO.

[17] Kreitz-Sandberg, S. (2016). Improving pedagogical practices through gender inclusion: Examples from university programmes for teachers in preschools and extended education. International Journal for Research on Extended Education. 4 (2). 71-91.

[18] Eurydice, (2009). Gender differences in educational outcomes: Study on the measures taken and the current situation in Europe, European Commission, EACEA 9, Brussels, Germany.

[19] Miske, S. (2013). Gendered dimensions of teaching and learning: UNGEI gender monitoring report background paper for EFA-Gender Monitoring Report 2013: UNGEI.

[20] Rutoro, E. Jenjekwa, V. Julius, R. \& Chipato, R. (2013). Gender equity dilemma and teacher education in Zimbabwe: The quest for justice. International Journal of Education and Research, 1 (10). 1-14.

[21] Lahelma, E. \& Tainio, L. (2019). The long mission towards gender equality in teacher education: Reflections from a national project in Finland, University of Helsinki, Faculty of Education and the Nordic Centre of Excellence, Nordic Studies in Education, 2019.

[22] Mägi, E. Biin, H. Trasberg, K. \& Kruus, K. (no date). Gender awareness and attitudes towards gender equality among students participating in teacher training, Praxis Centre for Policy Studies, Tornimae, 5, 10145 Tallinn, Estonia. 
[23] Ananga, E. D. (2021). Gender responsive pedagogy for teaching and learning; The practice in Ghana's initial teacher education programme. Creative Education. 12: 848-864.

[24] Oslen, C., \& St. George, D. M. (2004). Cross-sectional study design and data analysis. The Young Epidemiology Scholars Program (YESP), Robert Wood Johnson Foundation and Administered by the College Board, Iowa and Chicago, USA.

[25] Cohen, L. Manion, L. \& Morrison, K. (2000). Research methods in education, Routledge/Falmer, London and New York.

[26] Rubin, H. J. \& Rubin, I. S. (2005). Qualitative interviewing, The art of hearing data (2nd Edition), Thousands of Oaks, CA. Sage, London.

[27] Abril, P., Cremers, M. Duncan, N. Golubevaite, L. Krabel, J.
Lilaite, A. Nordfjell, O. B., Raudonyte, J., \& Romero, A. (2008). Gender loops: Toolbox for gender conscious and equitable early childhood centres. Hinkelsteinsteindruck Sozialistische GmbH, Berlin, Germany.

[28] Muasya, J. N. \& Kazungu, T. W. (2018). 'The unfinished business': Exploring teachers' views on gender and pedagogical practices in public preschools in Nairobi County, Kenya. African Educational Research Journal, 6 (1). 10-19.

[29] Republic of Kenya (2019). Sessional paper no. 1 of 2019, on policy framework for reforming education and training for sustainable development in Kenya, Government Printers, Nairobi, Kenya.

[30] African Union (2016). Continental education strategy for Africa (CESA) (2016-2025). 